\title{
A REVIEW OF OPTIMISATION OF MORPHING SURFACES FOR INCREASED AERODYNAMIC PERFORMANCE
}

\section{K. Z. MIRZA}

Mukesh Patel School of Technology Management \& Engineering, Mumbai, Maharashtra - 400058, India

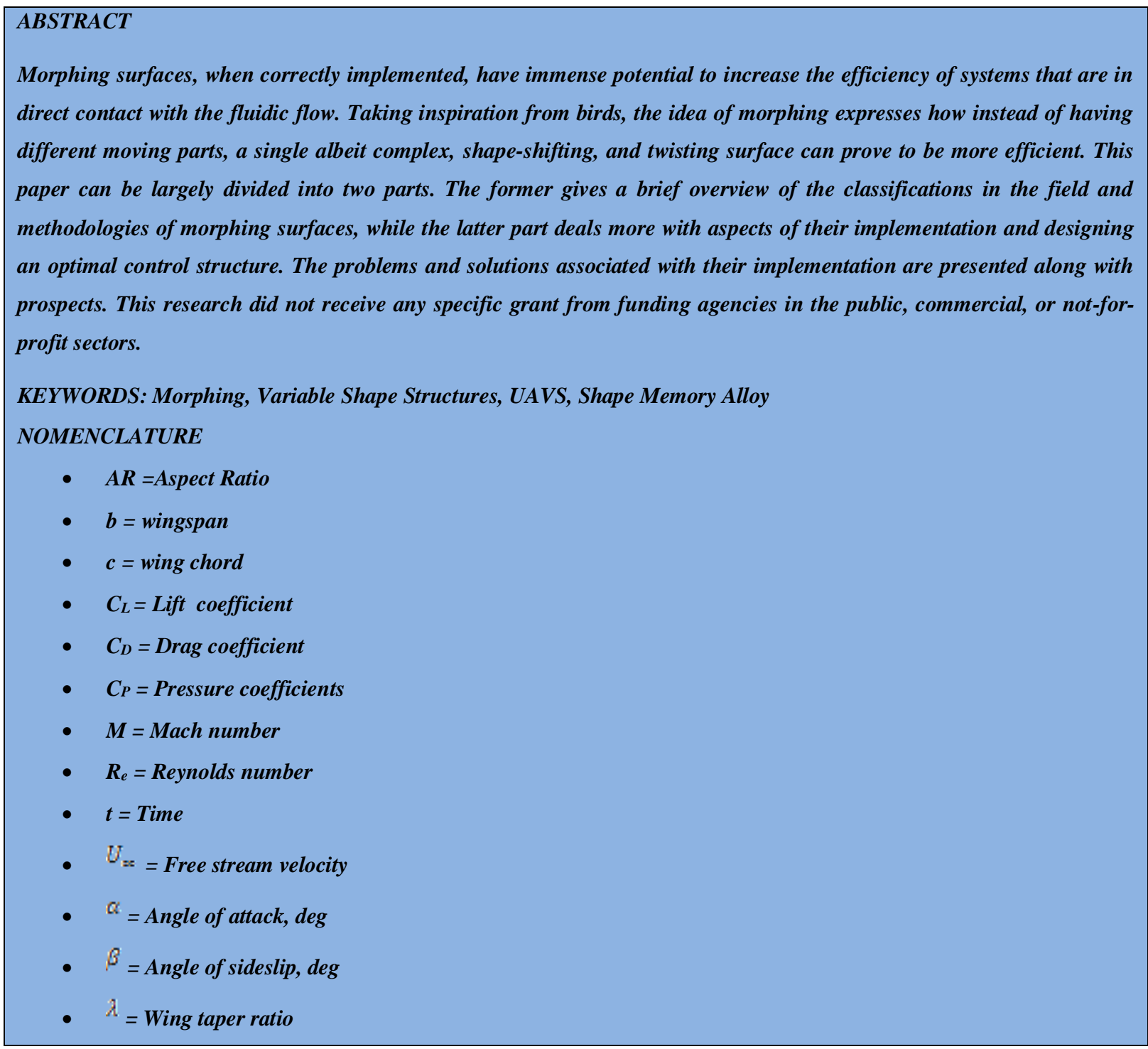

Received: Jun 08, 2020; Accepted: Jun 28, 2020; Published: Sep 16, 2020; Paper Id.: IJMPERDJUN20201265

\section{INTRODUCTION}

Morphing techniques or similar actively deployable surfaces are highly dependent on an integrated sensor network. However, such a nexus of sensors has its limitations such as

- Cable management complexities

- System integrity in cases where a series configuration is required over its parallel counterpart 
- Maximum cap on the strain allowance, especially in cases where a super-deformable material is to be used.

- Unreliable silicones and foam bonding

Certain workaround methods for the above solution exist, such as employing a wireless system thereby making the integration and installation of sensors far more manageable, removing the need for architecture unpacking. Such a methodology would take advantage of the simplicity with which sensor nodes can be placed and made to adapt.Wireless sensor network (WSN) refers to a group of spatially dispersed and dedicated sensors for monitoring and recording the physical conditions of the environment and organizing the collected data at a central location [1, 2]. Such a system would also bring about additional problems, for instance, mutual interference and high transmission power.

For high curvature surfaces, spraying of sensors can make them independent of geometric shapes. Spraying methods have evolved drastically from uncontrollable to present-day pressurized systems. In cold spraying process, a

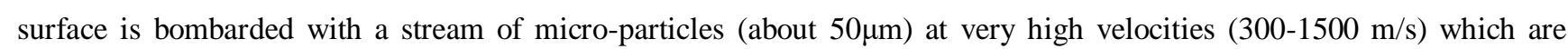
driven through a gas in a pressurized chamber, below the melting point of the material. Cold sprays, by employing low temperatures, minimize the effects of residual stress and excess gas release and their low oxygen levels contribute to them exhibiting bulk-like properties for electrical and thermal conductivity.

By ceaseless monitoring at substructural levels, reliable data about the integrity of each system can be procured down to $5 \mathrm{~mm}$. This can be accomplished by using fiber optic cables and their backscattered light. For larger components, [3] utilized the time of the backscattered light to know the location of the reflection. Other improved methods can also be seen in $[4-6]$

For ease of understanding, consider every rib in the trailing edge of a morphing wing is connected by actuation mechanisms, which in turn are connected to a longitudinal stiffening element. As proposed in [7], such a mechanism, known as oscillatory glyph mechanism would prove to be efficient and robust at the same time by making the actuation rod oscillate between two extreme positions at different speeds, and hence have a widespread use where a quick return mechanism was required. In paper [8], the same design was modified which mainly relied on the reversal of the mechanism itself. Other such applications include the SARISTU (Smart Intelligent Aircraft Structures) and CRIAQ (Consortium for Research and Innovation in Aerospace) projects undertaken by Airbus and Bombardier respectively. The SARISTU project revolved around the creation of an adaptive trailing edge device (ATED) using Fiber Bragg gratings using closed-loop control to achieve a given set of target cambers. The shape information is converted into strain information using an optical fiber transducer. The shape sensor consists of a beam running laterally with slots for housing the optical fiber cable on the upper and lower parts. Consisting of four support joints, the first and major support is affixed while the rest form the required camber of the ATED. All supports are directly joint to the inner skin surfaces. The sensor assembly is designed to follow the morphing of the ATED. To obtain the shape of the sensing strip at a particular stress level, the Frenet - Serret formulas are used.

Differential geometry principles demonstrate that a "shape" can be defined as a group of scalar and vector quantities along a curvilinear abscissa $(\mathrm{s})$ : the curvature $\kappa(\mathrm{s})$, torsion $\tau(\mathrm{s})$, tangent vector $\mathrm{T}(\mathrm{s})$, normal vector $\mathrm{N}(\mathrm{s})$, binormal vector $\mathrm{B}(\mathrm{s})$, and position vector $\mathrm{r}(\mathrm{s})$. This means that given the relation between the strain at a certain location $\varepsilon(\mathrm{s})$, and the half-thickness of the Sensor Beam ymax: 


$$
k(s)=\frac{\varepsilon(s)}{y \max }
$$

And the Frenet - Serret formulas can be applied as-

$$
\frac{d}{d x} \vec{T}=k(s) \vec{N}(s) \frac{d}{d x} \vec{N}(s)=-k(s) \vec{T}(s)+\tau(s) \vec{B}(s) \frac{d}{d x} \vec{B}(s)=\tau(s) \vec{N}(s)
$$

With the initial values of $\mathrm{T}(0), \mathrm{N}(0)$, and $\mathrm{B}(0)$, the shape can be reconstructed by iteration where the position vector $\mathrm{r}(\mathrm{s})$ of the sensor beam is computed by:

$$
\vec{r}(s)=\int_{0}^{s} T(s) \cdot d s+\vec{r}(0)
$$

The SARISTU project proved to be a success with error $<4.3 \%$, which was within the design limitations

\section{DEVELOPING A CONTROL SYSTEM FOR MORPHING SURFACES}

Each morphing model proposed, required movement two stable states and transitions between them. For aerodynamic morphing, the major aim is to reach the desired camber value in flight, keeping in mind flight parameters like the resistance to the movement and the structure's in flight integrity without compromising efficiency. Dimin et al. [9] presented a solution by integrating a set of actuators into the trailing edge of the wing, with the main aim being to create a secondary method for transforming the camber between $+5^{\circ}$ and $-5^{\circ}$. Both feed forward and feedback control logic architectures were detailed and numerically investigated. And since morphing surfaces have the capability to surpass traditional aircraft control surfaces, the flight dynamics of the same have been studied. Li et al. [10] developed a controller encompassing the ability to morph both, the leading and the trailing edge by using two actuators and hence overcoming longitudinal instability. Fig (4) shows a simple block diagram devised for a controlling mechanism for a closed-loop system. Tong et al. [11] created a system for variable span morphing aircraft by asymmetric changes in the wing sweep angle. By using Kane's method, a multibody dynamic model was built and constrained back stepping methods were used for trajectory tracking. The stability of the presented control law was discussed in the sense of Lyapunov. Liu et al. [12] developed a system specifically for a certain type of morphing surfaces where distributed arrays of multiple shape-changing devices were used. In the domain of folding wings, Colorado et al. [13] described a system including an attitude controller named backstepping encompassing angular acceleration functions. Simulations showed a $23 \%$ increase in net force production. For designing a control system for the actuation and sensor architecture, we look at data obtained from SMA models [14] by giving inputs such as initial alloy temperature, the applied force, and the heat generated due to the current and outputs such as actuator temperature and its displacement. For using the SMA's shape-changing characteristics, an initialization was required by an external force to pass it through the transformation phase and then subsequently into the cooling phase. In $[15,16]$, the controller had jurisdiction on the operation of the airfoil camber, and hence open loop. For each airfoil, there would be two values which would give the magnitude of the difference between the optimum and present vertical elongations at the 2 actuating points (assume $\mathrm{W}_{1} \& \mathrm{~W}_{2}$ ) where the optimum displacement would be $\mathrm{Y}_{1} \& \mathrm{Y}_{2}$. Koreanschi et al. [17] used this method of two actuating points along with an adaptive upper surface to minimize the shift between the values of $C_{L}$ and $C_{D}$ while transitioning from laminar flow to turbulent flow. To accomplish this, a linear variable differential transformer [LVDT] potentiometers were used. The open-loop control was designed, to equal the actual elongations i.e, $\mathrm{X}_{1} \& \mathrm{X}_{2}$ to the optimum displacement by enabling the SMA to control the elongation till the optimal point 
is reached. [15, 18-25]. The schematic is depicted in fig (5). Closed Loop control systems are used for real-time airfoil generation, using information such as pressure to improve the steady-state fluid flow over the upper surface of the airfoil (fig (6)). The optimum airfoils calculated previously are used as reference points and the closed-loop system is allowed to calculate its steady points, which are then compared to the known values.

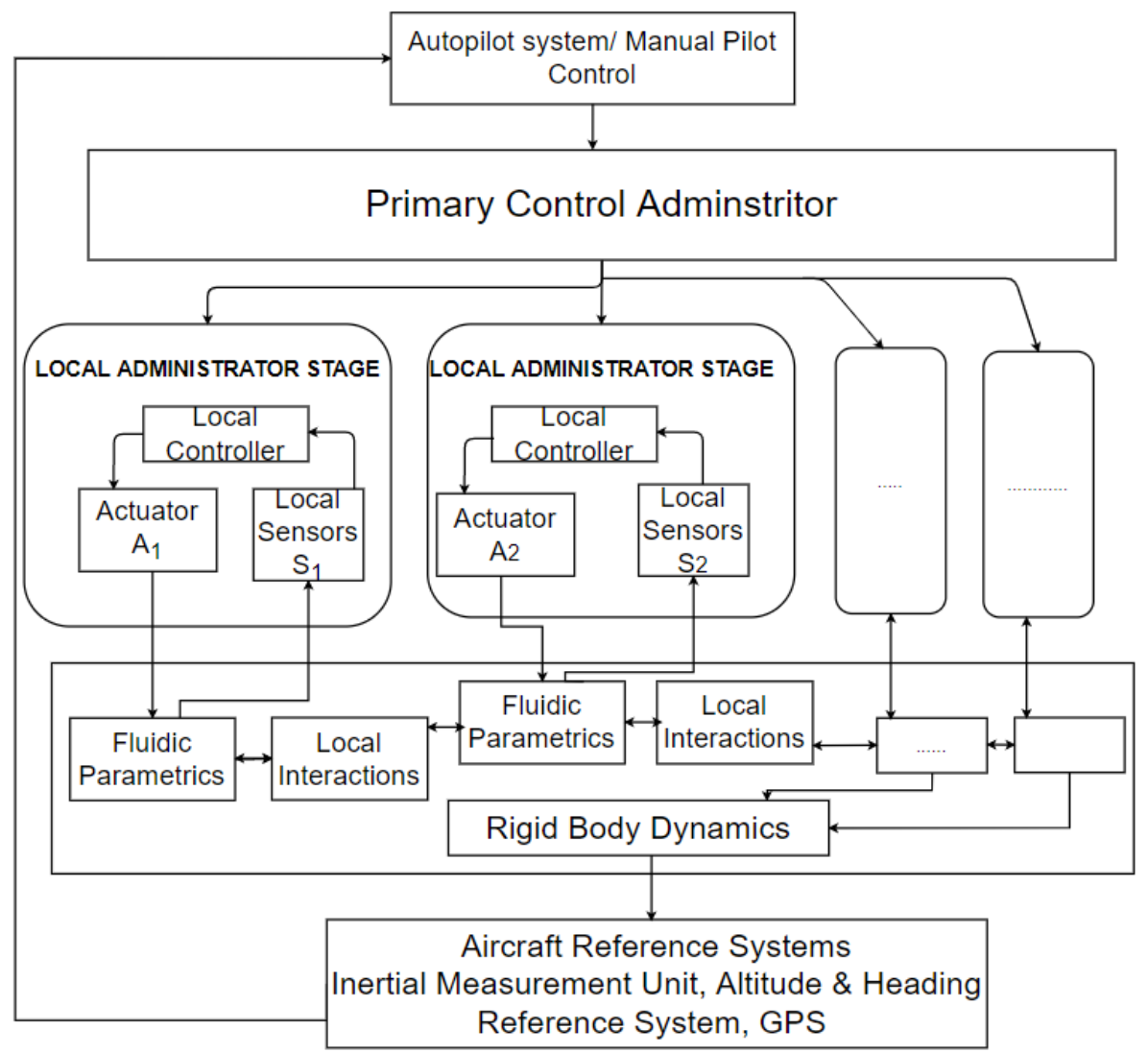

Figure 1: Simple Block Diagram Devised for a Controlling Mechanism for a Closed-Loop System.

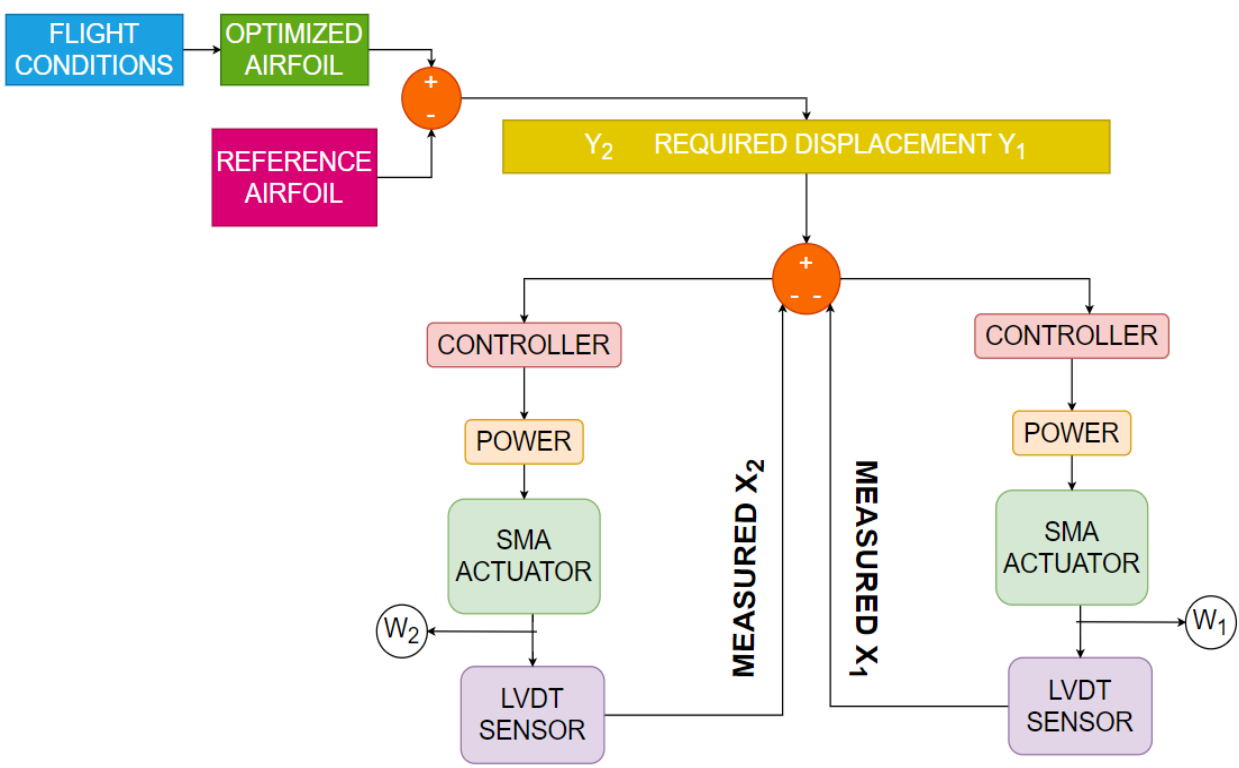

Figure 2: Open-Loop Control System. 
Here two branches i.e, gradient ascent and simulated annealing are merged [29] because the cost function depends on the decrement of the $C_{D}$ and maximization of $C_{L} / C_{D}$, and hence a gradient ascent method alone was not suitable. Not only was it more accurate, but this structure also proved to be faster in terms of determining the value of the transition points.

\section{Optimization Control}

Designing a morphing surface is always a balancing act between the weight, power consumption, cost, and the effectiveness of the system itself. Thus the objective functions can be classified topology optimization [30-32], parameter or gradient-based optimization, and evolutionary optimization algorithms.

Topology optimization is generally utilized for morphing the leading and trailing edges. Tong et al. [31] devised a system for leading-edge morphing by using glass fiber reinforced epoxy composites, built by using solid isotropic material with penalization (SIMP) method and an objective function was used to minimize the LSE between the deformed and desired camber values. Multi-objective population-based increment methods were used to find the optimal percentage of change in the $\mathrm{C}_{\mathrm{L}}$, buckling factor, and the total mass of the structure. Gradient-based optimization is often used along with another method that is concerned with computing the required roots of the derivatives for a given aerodynamic situation. Nitin et al. [33] proposed a shape optimization tool for 3D lifting surfaces for operations in viscous and incompressible environments. A flapping wing configuration as described previously was considered in [34] for maximizing the propulsive efficiency. Zhoujie et al. [35] quantified the results of the aerodynamic analysis and highlighted the benefits of using a trailing edge configuration along with aerodynamic design optimization. However, the most widespread method for morphing is evolutionary-based. By using parameters for describing, the external planform of the wing section, the actuator along their positions, and internal compliant structure, Molinari et al [37] showed an approach to optimization.

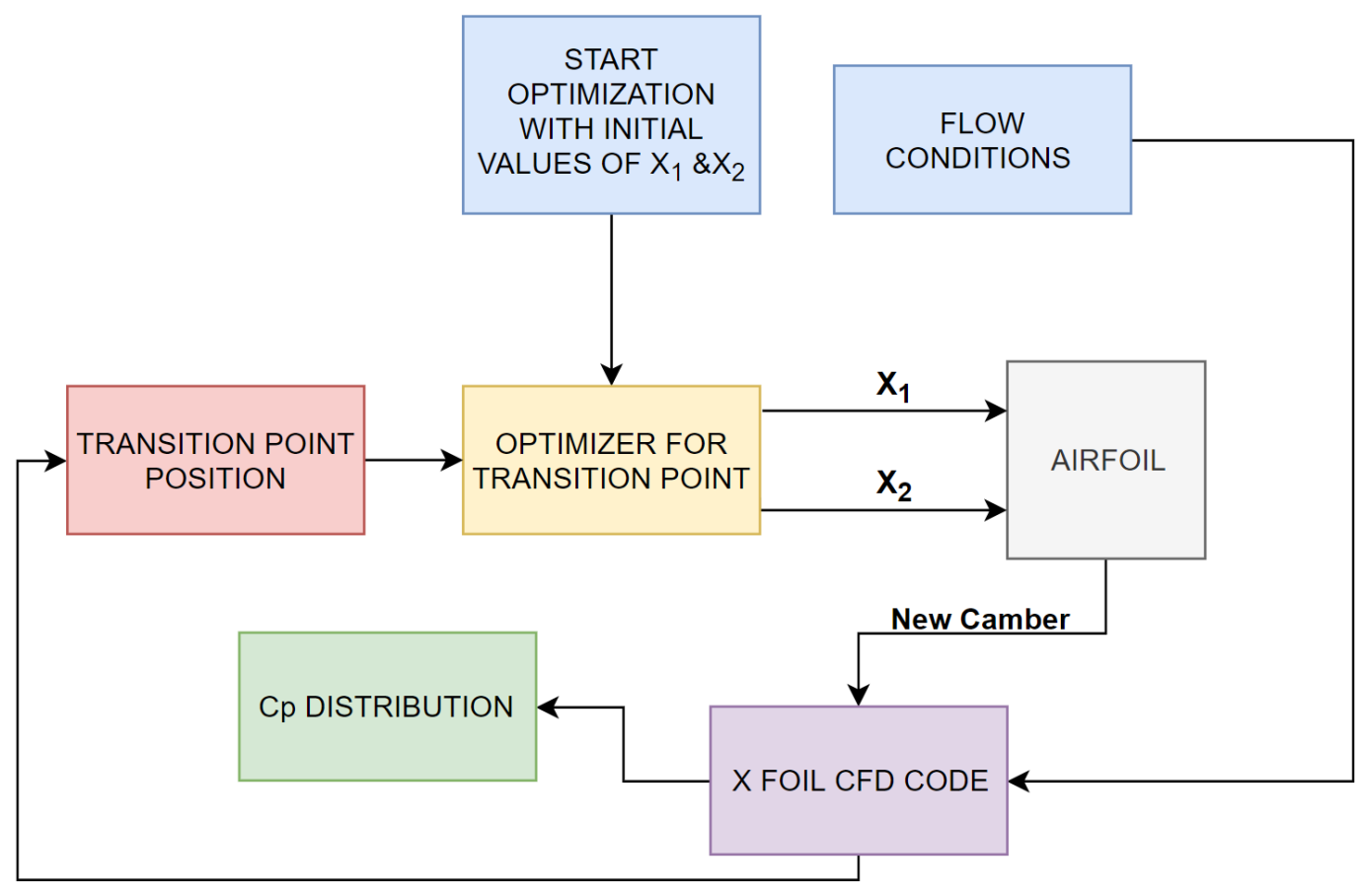

Figure 3: Closed-loop Control System. 
The wing was actuated using SMA embedded into the structure and the internal compliant structure used primarily for guiding the morphing is described by a Voronoi graph-based parameterization. Thus by using a combined approach, the resulting airfoil section can produce a morphed cambered airfoil, when actuated and also when inactive, hence providing the required aerodynamic efficiency. Kai et al. proposed a method for approximating a shape change of morphing surfaces, by using revolute joints in conjunction with prismatic joints. The NOVEMOR PROJECT [38] showed certain optimization tools could be developed to judge the parameters of a morphing wing. Gaspari et al. presented an optimal network for estimation of the camber, by combining genetic algorithms, modeling, and geometrical representation. For obtaining a more complete estimation of the aerodynamic work done and an overall energy model for morphing wings, Hwoong et al. [41] created a model with a simple spring system. These newer systems were also used in an attempt to make subsonic high altitude flight models In an attempt to minimize drag production rates and the required actuation energy. Botez et al. [43] showed the numerical analysis of a wing section, originally based on the airfoil shape of the ATR 42 , and the effective testing of two models, and a third morphing wing section from the same original airfoil, to be tested specifically for speeds below Mach 0.1 and an angle of attack of equal to or less than $0.1^{\circ}$. Wu et al. [44] formulated a method for the creation and optimization of a morphing wing with 2 steady states using an immune genetic algorithm (IGA). The system could provide an optimal solution due to the function of vaccination and immune selection in IGA. The conception of IGA is embedded in the optimization process of the new method, represented in the red box. Kai et al. [47] showed a different method for better shape approximation using rigid-body topologies.

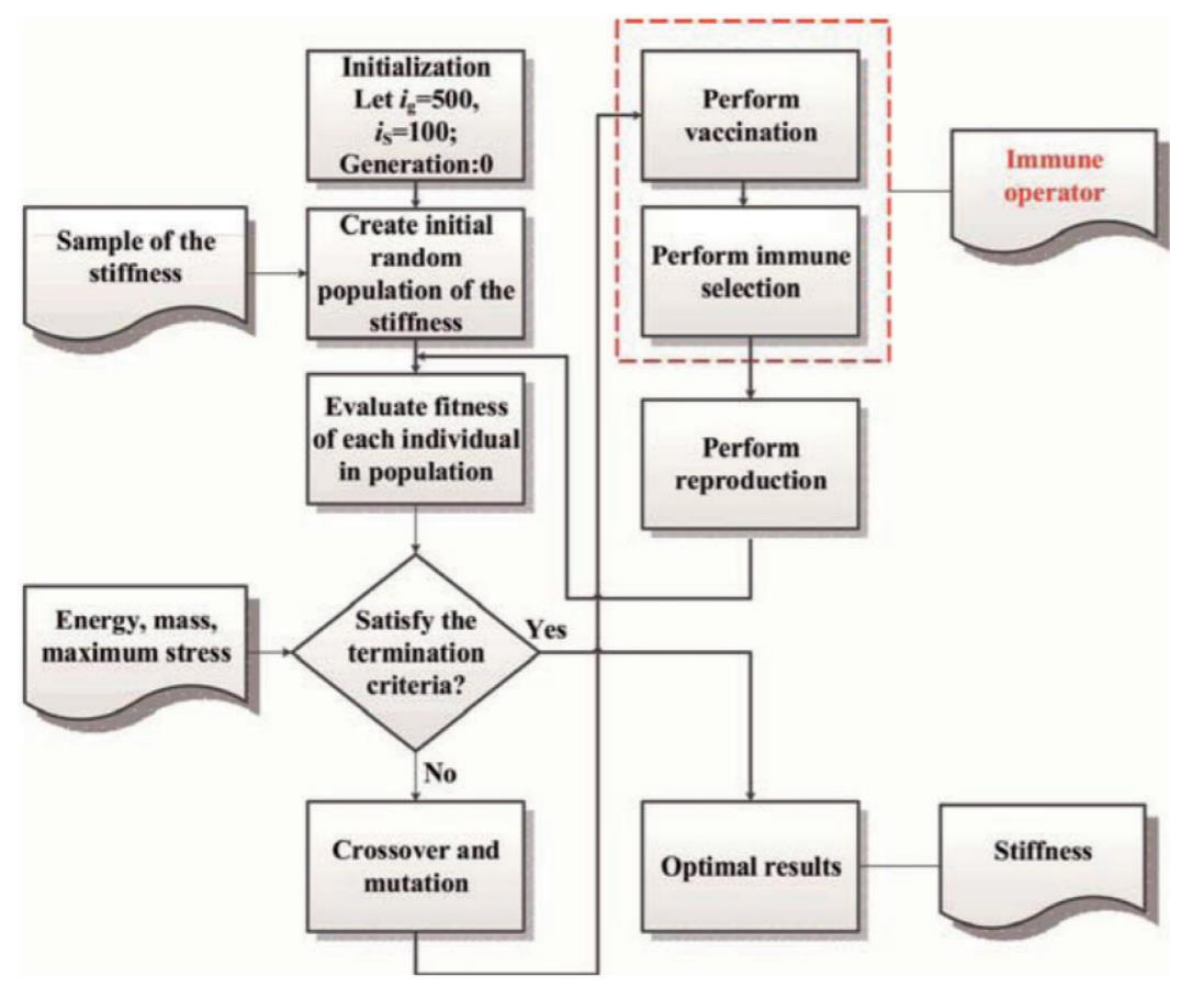

Figure 4: Optimization Control as Described in [45].

\section{Assembly}

Morphing structures and surfaces are no exception to the bounds of low tolerances and critical activity. The eventual product must be under general aviation safety parameters and compliant with the design specifications [48]. Wing structures generally embody the largest number of components in an aircraft: ribs, spars, panels, clips, doublers, and 
stringers [49]. Bi actuator systems are common albeit, the number, nature, and permutations of components used cannot be generalized. Each system can be expected to contain:

- An adaptive skin

- $\quad$ Fiber optic networks

- An actuator system

- A sensor system

- Power transmission

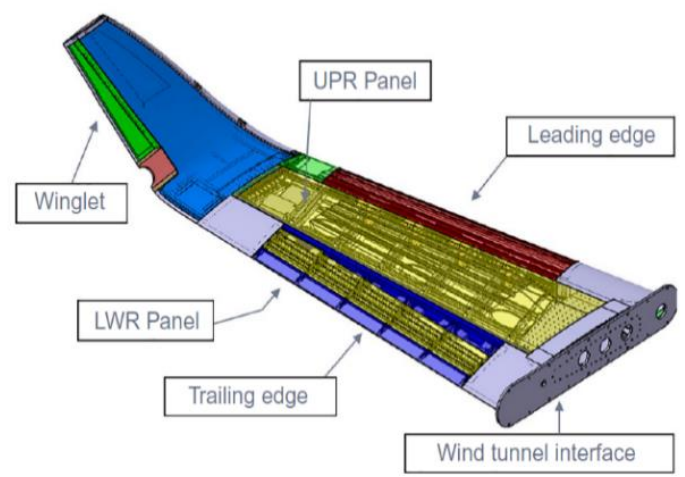

Figure 5: CAD Representation of the Wing Structure.

The wing box was made with a fully integrated fiber-optic system for detecting its structural health. The adaptive leading edge was made for improving take-off and landing performance as an alternative to conventional mechanical slats [51]. The trailing edge would be used for changing the camber in flight, to compensate with weight reduction related to the fuel consumption with its movement driven by equidistributed actuator configurations [52]. The adaptive trailing edge of the winglet helps with the load distribution over the wing and balanced gusts effect [53]. Fig (8) and fig (9) show a pictorial representation and schematic diagrams respectively.

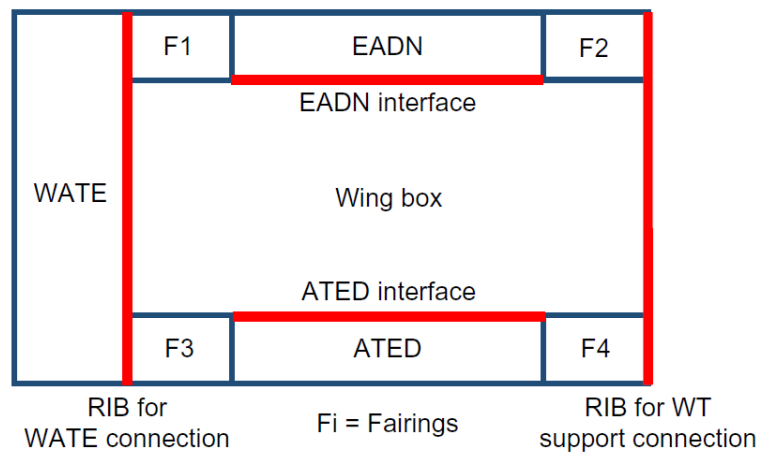

Figure 6: Schematic of an Adaptive Wing [50].

\section{Wing box}

For testing a wing box in a wind tunnel [50] took extra measures by taking care to manufacture components which were resistant to any mishaps during the testing. It was also necessary to support the adaptive parts and it needed to be rigid 
enough to disallow coupling and deformation under aerodynamic loads. By applying the said considerations to the ribs, panels and the wingtip's trailing edge, the main components of the wing box can be listed as two fiber-optic networks, multiple ribs running longitudinally from the dropping leading edge to the morphing trailing edge; top and bottom panels along with front and rear spars. The outer skin materials may vary from fixed to adaptable to SMA.

\section{Leading edge}

Consisting of a fiberglass structure that was highly deformable under external forces, the leading edge was connected by ribs, whose movement would produce the necessary actuation. The movement of the ribs was controlled by a motor through shafts. This specific arrangement was placed between the top and bottom panels of the wing box and its front spar caps and another line of joints between the web of two and a half spars where each was associated with the wing box and the leading edge respectively. There is no interference between the shape-changing portion and the fixed parts of the wing box. But the morphing leading-edge system could not be extended across the whole wing's surface due to complications in space and the machinery of the morphing wingtip.

\section{Trailing edge}

The main driving force was derived from transmission kinematics linked with actuators. This new architecture, consisting of dedicated motors and other embedded active systems could be completely allocated into the morphing section at a reasonable expense and maintenance cost. Another advantage of fitting the whole system into the morphing part is that the system will either work as a whole or fail completely. However, the probability of a single actuator failing alone is much higher than that of ten of them failing together. Also, by using such a multi-motor configuration, variable values of camber can be achieved along the wing, latitudinally, thereby providing a wing twist. The adaptive trailing edge increased efficiency by providing optimum trim and simultaneously weighing less, thereby reducing the required fuel.

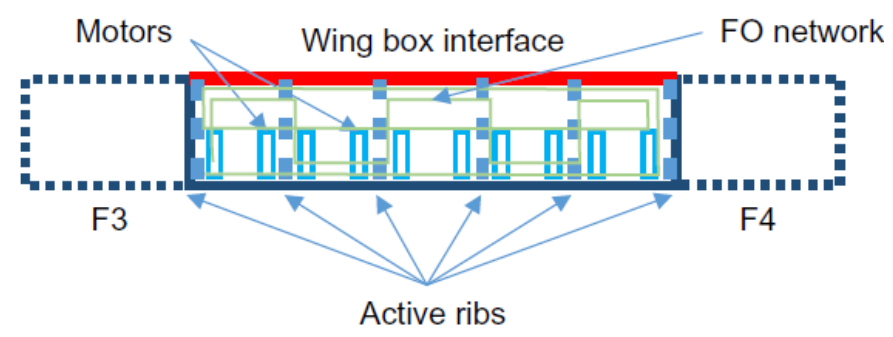

Figure 7: Trailing Edge Mechanism [50].

\section{Wingtip}

The morphing wingtip structure consisted of a traditional wingtip with its trailing edge acting as a tab, with all the devices associated with the movement of the tab embedded into the structure similar to a flap. In all, the structure consisted of an elastic link between the moving part and the rigid system, motor, shaft, and a deformable structure. The deforming part of the structure is excited through cables which in real-life applications would be difficult to house inside the wing. The LE consisting of anti-icing and leading-edge morphing systems while the TE has only the morphing mechanism but has little to no room left. The adaptive winglet is designed to achieve load distribution and gust effects attenuation but if the electronics are all housed in the wingtip itself it could lead to undesired aero elastic behavior. In addition, the winglet could also be used as a directional control surface, alleviating the rudder efforts. 


\section{FUTURE}

A morphing rudder's mechanism and development could soon be found, mainly for larger aircraft complete with additive manufacturing processes and orthotropic panels however, the testing phase provided uncertain results [54]. NASA and the Massachusetts Institute of Technology have recently presented 'MadCat'. It consists of thousands of small triangular blocks combined into a lattice-like structure for wing morphing. These blocks can build and rebuild an object giving it new shapes for specific tasks at any time. NASA and MIT developed a technology of composite injection molding in which the casting of one block takes 17 seconds instead of the previously needed several minutes. This easily scalable project is still far from the stage of industrial production but there have been tests of center equipped wings to monitor the airflow around the wing and continuously adjust its shape.

\section{CONCLUSIONS}

In this paper, different methods for controlling a morphing system and their assembly were discussed. Bi - actuator concepts integrated with a top surface made flexible by using a smart material for deformation seems like the most viable option and is being considered for further development. An only trailing edge morphing configuration would also find good use in flight operations. Although many concepts have been described above, only a handful of them were implemented on aircraft. Quite a few concepts for using morphing concepts on low-speed aircraft were conceived, but none were tested in flight. Since actuation systems can be bulky, any morphing system needs to overcome the barrier of weight. For low-speed aircraft, any such system should undergo a substantial change for any noticeable improvement in the aerodynamic properties while also being under the weight limit. For a successful conceptual design, it is important to have integrated and distributed actuators to avoid transmission mechanisms and using advanced light-weight composites for the fixed structure and the skin.

\section{REFERENCES}

1. Tamburrano, A., Sarasini, F., De Bellis, G., D'Aloia, A. G., \&Sarto, M. S. (2013). The piezoresistive effect in graphene-based polymeric composites.Nanotechnology, 24(46), 465702. doi:10.1088/0957-4484/24/46/465702

2. Yick, J., Mukherjee, B., \&Ghosal, D. (2008). Wireless sensor network survey. Computer Networks, 52(12), 2292-2330. doi:10.1016/j.comnet.2008.04.002

3. Galindez-Jamioy, C. A., \&López-Higuera, J. M. (2012). Brillouin Distributed Fiber Sensors: An Overview and Applications. Journal of Sensors, 2012, 1-17. doi:10.1155/2012/204121

4. Soller, B. J., Gifford, D. K., Wolfe, M. S., \& Froggatt, M. E. (2005). High resolution optical frequency domain reflectometry for characterization of components and assemblies. Optics Express, 13(2), 666. doi:10.1364/opex.13.000666

5. http://www.fbgs.com/products/draw-tower-gratings/overview/.

6. Liao, C. R., \& Wang, D. N. (2012). Review of femtosecond laser fabricated fiber Bragg gratings for high temperature sensing. Photonic Sensors, 3(2), 97-101. doi:10.1007/s13320-012-0060-9

7. Shelare SD, Handa C. Tsynthesis, simulation and sensitivity analysis of quick return mechanism. LAP LAMBERT Academic Publishing: December 2012.

8. Dimino, I., Flauto, D., Diodati, G., Concilio, A., \&Pecora, R. (2014). Actuation System Design for a Morphing Wing Trailing Edge. Recent Patents on Mechanical Engineering, 7(2), 138-148. doi:10.2174/2212797607666140429005538 
9. Dimino, I., Concilio, A., Schueller, M., \&Gratias, A. (2013). An adaptive control system for wing TE shape control.Industrial and Commercial Applications of Smart Structures Technologies 2013. doi:10.1117/12.2012187

10. Shah, SAMKIT V., et al. "Aerodynamic and Thermal Design of Centrifugal Compressor for Small Scale in Non-Dimemsional Form." Int. J. Mech. Prod. Eng. Res. Dev 7 (2017): 81-92.

11. Li, D., Guo, S., Aburass, T. O., Yang, D., \& Xiang, J. (2016). Active control design for an unmanned air vehicle with a morphing wing. Aircraft Engineering and Aerospace Technology, 88(1), 168-177. doi:10.1108/aeat-12-2013-0234

12. Tong, L., \& Ji, H. (2014). Multi-body dynamic modelling and flight control for an asymmetric variable sweep morphing UAV. The Aeronautical Journal, 118(1204), 683-706. doi:10.1017/s000192400000943x

13. Liu, C., \& Zhang, S. (2013). Novel robust control framework for morphing aircraft.Journal of Systems Engineering and Electronics, 24(2), 281-287. doi:10.1109/jsee.2013.00035

14. Colorado, J., Barrientos, A., Rossi, C., \& Parra, C. (2013). Corrigendum: Inertial attitude control of a bat-like morphing-wing air vehicle. Bioinspiration \& Biomimetics, 8(1), 019502. doi:10.1088/1748-3190/8/1/019502

15. Sreelakshmi, K., and B. Niharika. "Design and Analysis of mini-UAV." International Journal of Mechanical and Production Engineering Research and Development (IJMPERD) 8.1 (2018): 1-8.

16. Grigorie, T. L., \&Botez, R. M. (2018). Control Techniques for a Smart Actuated Morphing Wing Model: Design, Numerical Simulation and Experimental Validation. Morphing Wing Technologies, 351-397. doi:10.1016/b978-0-08-100964-2.00012-5

17. Grigorie, T. L., Popov, A. V., Botez, R. M., Mamou, M., \&Mébarki, Y. (2011). Design and Experimental Validation of a Combined PI and Bi-Positional Laws Controller for Delaying the Transition from Laminar Flow to Turbulent Flow over a Morphing Wing. Lecture Notes in Electrical Engineering, 51-76. doi:10.1007/978-3-642-19539-6_4

18. Grigorie, L. T., \&Botez, R. M. (2014). Control strategies for an experimental morphing wing model. AIAA Atmospheric Flight Mechanics Conference. doi:10.2514/6.2014-2187

19. Jagadeesh, V., and J. Sandeep. "Aerodynamic Study of Span Wise Morphing Wing. "International Journal of Mechanical and Production Engineering Research and Development (IJMPERD) 9.6, Dec 2019, 443-450

20. Koreanschi, A., Sugar-Gabor, O., \&Botez, R. M. (2016). Drag optimisation of a wing equipped with a morphing upper surface. The Aeronautical Journal, 120(1225), 473-493. doi:10.1017/aer.2016.6

21. Botez, R., Grigorie, T., Popov, A., Mamou, M., \&Mébarki, Y. (2011). A New Morphing Wing Mechanism Using Smart Actuators Controlled by a Self-Tuning Fuzzy Logic Controller. AIAA Centennial of Naval Aviation Forum "100 Years of Achievement and Progress." doi:10.2514/6.2011-7071

22. Grigorie, T. L., \&Botez, R. M. (2009). Adaptive neuro-fuzzy inference system-based controllers for smart material actuator modelling. Proceedings of the Institution of Mechanical Engineers, Part G: Journal of Aerospace Engineering, 223(6), 655668. doi:10.1243/09544100jaero522

23. Grigorie, L., Botez, R., Popov, A., Mamou, M., \&Mebarki, Y. (2011). An Intelligent Controller based Fuzzy Logic Techniques for a Morphing Wing Actuation System using Shape Memory Alloy. 52nd AIAA/ASME/ASCE/AHS/ASC Structures, Structural Dynamics and Materials Conference. doi:10.2514/6.2011-2133

24. Martin, Shynee, et al. "Growth of Literature on Aerodynamic Research: A Scientometrics Study. "International Journal of Library Science and Research (IJLSR) 7. 2, Apr 2017, 45-56

25. Grogorie, L., Popov, A., \&Botez, R. M. (2013). Control of Actuation System Based Smart Material Actuators in a Morphing Wing Experimental Model. AIAA Atmospheric Flight Mechanics (AFM) Conference. doi:10.2514/6.2013-4918. 
26. Grigorie, T. L., Botez, R. M., Popov, A. V., Mamou, M., \&Mébarki, Y. (2012). A hybrid fuzzy logic proportional-integralderivative and conventional on-off controller for morphing wing actuation using shape memory alloy Part 1: Morphing system mechanisms and controller architecture design. The Aeronautical Journal, 116(1179), 433-449. doi:10.1017/s0001924000006977

27. Grigorie, T. L., Botez, R. M., Popov, A. V., Mamou, M., \&Mébarki, Y. (2012). A hybrid fuzzy logic proportional-integralderivative and conventional on-off controller for morphing wing actuation using shape memory alloy Part 2: Controller implementation and validation. The Aeronautical Journal, 116(1179), 451-465. doi:10.1017/s0001924000006989

28. Grigorie, L., Botez, R. M., \& Popov, A. V. (2016). Self-adaptive morphing wing model, smart actuated and controlled by using a multiloop controller based on a laminar flow real time optimizer. 24th AIAA/AHS Adaptive Structures Conference. doi:10.2514/6.2016-1082

29. Popov, A. V., Labib, M., Fays, J., \&Botez, R. M. (2008). Closed-Loop Control Simulations on a Morphing Wing. Journal of Aircraft, 45(5), 1794-1803. doi:10.2514/1.37073

30. Popov, A. V., Grigorie, T. L., Botez, R. M., Mébarki, Y., \&Mamou, M. (2010). Modeling and Testing of a Morphing Wing in Open-Loop Architecture. Journal of Aircraft, 47(3), 917-923. doi:10.2514/1.46480

31. Popov, A. V., Grigorie, L. T., Botez, R., Mamou, M., \&Mébarki, Y. (2010). Closed-Loop Control Validation of a Morphing Wing Using Wind Tunnel Tests. Journal of Aircraft, 47(4), 1309-1317. doi:10.2514/1.47281

32. Popov, A. V., Grigorie, L. T., Botez, R., Mamou, M., \&Mebarki, Y. (2010). Real Time Morphing Wing Optimization Validation Using Wind-Tunnel Tests. Journal of Aircraft, 47(4), 1346-1355. doi:10.2514/1.47431

33. Lones, M. (2011). Sean Luke: essentials of metaheuristics. Genetic Programming and Evolvable Machines, 12(3), $333-334$. doi:10.1007/s10710-011-9139-0

34. Vasista, S., \& Tong, L. (2014). Topology optimisation via the moving iso-surface threshold method: implementation and application. The Aeronautical Journal, 118(1201), 315-342. doi:10.1017/s0001924000009143

35. Tong, X., Ge, W., Sun, C., \& Liu, X. (2014). Topology optimization of compliant adaptive wing leading edge with composite materials. Chinese Journal of Aeronautics, 27(6), 1488-1494. doi:10.1016/j.cja.2014.10.015

36. Sleesongsom, S., Bureerat, S., \& Tai, K. (2013). Aircraft morphing wing design by using partial topology optimization. Structural and Multidisciplinary Optimization, 48(6), 1109-1128. doi:10.1007/s00158-013-0944-3

37. Garg, N., Kenway, G. K. W., Lyu, Z., Martins, J. R. R. A., \& Young, Y. L. (2015). High-Fidelity Hydrodynamic Shape Optimization of a 3-D Hydrofoil. Journal of Ship Research, 59(4), 209-226. doi:10.5957/josr.59.4.150046

38. Stanford, B., \&Beran, P. (2009). Analytical Sensitivity Analysis of an Unsteady Vortex Lattice Method for Flapping Wing Optimization.50th AIAA/ASME/ASCE/AHS/ASC Structures, Structural Dynamics, and Materials Conference. doi:10.2514/6.2009-2614

39. Lyu, Z., \& Martins, J. (2014). Aerodynamic Shape Optimization of an Adaptive Morphing Trailing Edge Wing.15th AIAA/ISSMO Multidisciplinary Analysis and Optimization Conference. doi:10.2514/6.2014-3275

40. De Gaspari, A., \& Ricci, S. (2011). A Two-Level Approach for the Optimal Design of Morphing Wings Based On Compliant Structures. Journal of Intelligent Material Systems and Structures, 22(10), 1091-1111. doi:10.1177/1045389x11409081

41. Molinari, G., Arrieta, A. F., \&Ermanni, P. (2014). Aero-Structural Optimization of Three-Dimensional Adaptive Wings with Embedded Smart Actuators. AIAA Journal, 52(9), 1940-1951. doi:10.2514/1.j052715 
42. Vasista, S., De Gaspari, A., Ricci, S., Riemenschneider, J., Monner, H. P., \& van de Kamp, B. (2016).Compliant structuresbased wing and wingtip morphing devices. Aircraft Engineering and Aerospace Technology, 88(2), 311-330. doi:10.1108/aeat-02-2015-0067

43. Zhao, K., Schmiedeler, J. P., \& Murray, A. P. (2012). Design of Planar, Shape-Changing Rigid-Body Mechanisms for Morphing Aircraft Wings.Journal of Mechanisms and Robotics, 4(4). doi:10.1115/1.4007449

44. De Gaspari, A., \& Ricci, S. (2015). Knowledge-Based Shape Optimization of Morphing Wing for More Efficient Aircraft. International Journal of Aerospace Engineering, 2015, 1-19. doi:10.1155/2015/325724

45. Namgoong, H., Crossley, W. A., \&Lyrintzis, A. S. (2012). Morphing Airfoil Design for Minimum Drag and Actuation Energy Including Aerodynamic Work. Journal of Aircraft, 49(4), 981-990. doi:10.2514/1.c031395

46. Sleesongsom, S., \&Bureerat, S. (2015). Morphing Wing Structural Optimization Using Opposite-Based Population-Based Incremental Learning and Multigrid Ground Elements. Mathematical Problems in Engineering, 2015, 1-16. doi:10.1155/2015/730626

47. Botez, R. M., Koreanschi, A., \& Sugar-Gabor, O. (2016). Numerical and experimental validation of a morphed wing geometry using Price-Païdoussis wind-tunnel testing - CORRIGENDUM. The Aeronautical Journal, 120(1230), 1335-1335. doi:10.1017/aer.2016.73

48. Wu, J., Yan, S., \&Gu, Y. (2014). On stability optimization of the deployable bistable compliant structures mounted in the morphing skin: Method and implementation. Proceedings of the Institution of Mechanical Engineers, Part C: Journal of Mechanical Engineering Science, 229(5), 943-956. doi:10.1177/0954406214541634

49. Olympio, K. R., \& Gandhi, F. (2012). Optimal Cellular Core Topologies for One-Dimensional Morphing Aircraft Structures.Journal of Mechanical Design, 134(8). doi:10.1115/1.4007087

50. Bharti, S., Frecker, M., \&Lesieutre, G. (2009). Optimal Morphing-Wing Design Using Parallel Nondominated Sorting Genetic Algorithm II. AIAA Journal, 47(7), 1627-1634. doi:10.2514/1.36003

51. Zhao, K., \&Schmiedeler, J. P. (2013). Using Rigid-Body Mechanism Topologies to Design Shape-Changing Compliant Mechanisms. Volume 6A: 37th Mechanisms and Robotics Conference. doi:10.1115/detc2013-12576

52. J.P. Fielding, Introduction to Aircraft Design, Cambridge University Press, Cambridge, ISBN 978-0-521- 65722-8, 2010. p. 259

53. F. Viadero, M. Ceccarelli (Eds.), New Trends in Mechanism and Machine Science: Theory and Applications in Engineering, Springer Science \& Business Media, Dordrecht, ISBN 978-9-400-74902-3, 2012. p. 809.

54. Iannuzzo, G., Russo, S., Apicella, A., Rossi, L., \& Esposito, S. (2018). Morphing Wing Integration.Morphing Wing Technologies, 619-646. doi:10.1016/b978-0-08-100964-2.00020-4

55. M. Kintscher, J. Kim, S. Storm, F. Peter, Assessment of the SARISTU enhanced adaptive droop nose, in: P.C. Woelcken, M. Papadopoulos (Eds.), Smart Intelligent Aircraft Structures (SARISTU), Proceedings of theFinal Project Conference, Springer International Publishing, Cham, ISBN 978-3-319-22413-8, 2016.

56. Pecora, R., Amoroso, F., Magnifico, M., Dimino, I., \&Concilio, A. (2016). KRISTINA: Kinematic rib-based structural system for innovative adaptive trailing edge. Industrial and Commercial Applications of Smart Structures Technologies 2016. doi:10.1117/12.2218516 
57. Wildschek, A., Storm, S., Herring, M., Drezga, D., Korian, V., \&Roock, O. (2015). Design, Optimization, Testing, Verification, and Validation of the Wingtip Active Trailing Edge. Smart Intelligent Aircraft Structures (SARISTU), $219-255$. doi:10.1007/978-3-319-22413-8_12

58. Castillo Acero, M. Á., de la Escalera, F. M., \& Essa, Y. (2018). Morphing Technology for Advanced Future Commercial Aircrafts. Morphing Wing Technologies, 585-618. doi:10.1016/b978-0-08-100964-2.00019-8 
